\title{
PENGARUH MOTIVASI, DAN LINGKUNGAN KERJA, TERHADAP KINERJA KARYAWAN, DENGAN KEPUASAN KERJA SEBAGAI VARIABEL MEDIASI PADA PT BNI LIFEINSURANCE
}

\author{
Bayu Dwilaksono Hanafi \\ PT BNI Lifeinsurance, Jakarta \\ bayu.dwilaksono24@gmail.com \\ Corry Yohana \\ Universitas Negeri Jakarta \\ corryyohana@unj.ac.id
}

\begin{abstract}
This study aims to examine the effect of motivation on employee performance, motivation to job satisfaction, motivation to employee performance with mediated by job satisfaction, work environment influence to employee performance, work environment to job satisfaction, work environment to employee performance mediated by job satisfaction, And the effect of job satisfaction on employee performance. The study was conducted at PT BNI Life Insurance employee benefit division, with a population of 322 people, the researchers took 220 people as a sample. This research method uses quantitative research using causal effect and primary data type. Data collecting technique by interview and observation with questionnaire media. Method of analysis using inferential statistic with parametric data type, and using Structural Equation Modeling (SEM). The result of the research shows that the motivation variable on employee performance has positive and significant effect because it has $t_{\text {-value }}$ 2.97> $t_{\text {-table }}$ 1.96. Likewise the motivation of job satisfaction has a value of $t_{\text {value }} 2.31>t$-table 1.96 which means motivation has a positive and significant impact on job satisfaction. Motivation on employee performance mediated by job satisfaction also have a significant effect with $t_{\text {value }}-2.32>t_{\text {-table }}$ 1.96. But on work environment variables on employee performance showed no effect and significant because t-value value $0.00<t_{\text {-table }} 1.96$. In working environment variable to job satisfaction have positive and significant influence with $t$-value value equal to 2.97> $t$-table 1.96. Likewise on work environment variables on employee performance with job satisfaction as a mediation variable has a value of $t$-value $3.36>t_{\text {-table }} 1.96$ which means that the positive work satisfaction mediate the relationship between the work environment on employee performance.Finally can be seen variable job satisfaction on employee performance with Value $t_{\text {-value }}-2.73>t_{\text {table }} 1.96$, so it can be interpreted job satisfaction variables have a positive and significant impact on employee performance.
\end{abstract}


Keywords: Motivation, Work Environment, Job Satisfaction, and Employee Performance

\begin{abstract}
ABSTRAK
Penelitian ini bertujuan untuk menguji pengaruh motivasi terhadap kinerja karyawan, motivasi terhadap kepuasan kerja, motivasi terhadap kinerja karyawan dengan dimediasi oleh kepuasan kerja, pengaruh lingkungan kerja terhadap kinerja karyawan, lingkungan kerja terhadap kepuasan kerja, lingkungan kerja terhadap kinerja karyawan yang dimediasi oleh kepuasan kerja, dan pengaruh kepuasan kerja terhadap kinerja karyawan. Penelitian ini dilakukan di PT BNI Life Insurance divisi employee benefit, dengan jumlah populasi 322 orang, peneliti mengambil 220 orang sebagai sampel. Metode penelitian ini menggunakan penelitian kuantitatif dengan menggunakan hubungan kausal (causal effect) dan jenis data primer.Teknik pengumpulan data dengan melakukan wawancara dan observasi dengan media kuesioner.Metode analisis menggunakan statistik inferensial dengan tipe data parametrik, dan menggunakan Structural Equation Modeling (SEM). Hasil penelitian menunjukan variabel motivasi terhadap kinerja karyawan berpengaruh positif dan signifikan karena memiliki nilai t-value $2.97>\mathrm{t}_{\text {- }}$ abel 1.96 . Begitupun motivasi terhadap kepuasan kerja memiliki nilai $t$ value $2,31>t$-tabel 1.96 yang berarti motivasi berpengaruh positif dan signifikan terhadap kepuasan kerja. Motivasi terhadap kinerja karyawan yang dimediasi oleh kepuasan kerja juga berpengaruh signifikan dengan nilai $t$-value-2.32 $>t_{-t_{a b e l}}$ 1.96.Namun pada variabel lingkungan kerja terhadap kinerja karyawan menunjukan tidak berpengaruh dan signifikan karena nilai t-value $0.00<\mathrm{t}_{\text {-tabel }}$ 1.96.Pada variabel lingkungan kerja terhadap kepuasan kerja memiliki pengaruh positif dan signifikan dengan nilai t-value sebesar $2.97>t$ tabel 1.96. Begitupun pada variabel lingkungan kerja terhadap kinerja karyawan dengan kepuasan kerja sebagai

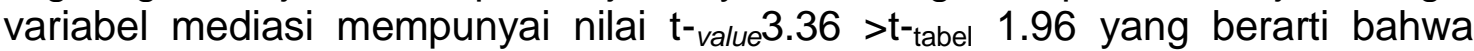
kepuasan kerja positif memediasi hubungan antara lingkungan kerja terhadap kinerja karyawan.Terakhir dapat dilihat variabel kepuasan kerja terhadap kinerja karyawan dengan nilai $t_{-}$value-2.73 >t-tabel 1.96, jadi dapat diartikan variabel kepuasan kerja berpengaruh positif dan signifikan terhadap kinerja karyawan.
\end{abstract}

Kata Kunci: Motivasi, Lingkungan Kerja, Kepuasan Kerja, dan Kinerja Karyawan

\section{PENDAHULUAN}

Pada kondisi saat ini perusahaan-perusahaan cenderung mengalami penurunan kinerja, hal tersebut sering disebabkan oleh kegagalan manajemen dalam men- gelola karyawannya. Keberhasilan suatu perusahaan sangat ditentukan oleh tenaga sumberdaya manusia yang handal, oleh sebab itu perlu dikaji faktor-faktor apa saja yang 
dapat meningkatkan kinerja karyawan tersebut.

Tujuan dari setiap perusahaan adalah mendapatkan laba sebanyak-banyaknya, dan mengharapkan agar laba tersebut terus bertumbuh. Dalam meningkatkan kinerja karyawan, hendaknya manajemen mengetahui apa saja kebutuhan karyawannya.

Hal-hal tersebut berguna untuk memberikan kesan kepada karyawan bahwa mereka diperhatikan oleh perusaha-an tempat mereka bekerja, dan ikut ambil andil dalam mencapai tujuan perusahaan. Maka sejatinya tujuan perusahaan akan sejalan dengan tujuan karyawannya.

Seorang karyawan yang memiliki kinerja yang baik dapat menunjang tercapainya tujuan dan sasaran yang telah ditetapkan oleh perusahaan. Menurut Kiruja dan Elegwa (Kiruja, 2013) kinerja karyawan merupakan fungsi dari kemampuan dan motivasi, di mana kemampuan terdiri dari keterampilan, pelatihan dan sumber daya yang diperlukan untuk melakukan tugas dan motivasi digambarkan sebagai kekuatan batin yang mendorong individu untuk bertindak terhadap sesuatu.
Flippo (2001) menambahkan bahwa kinerja karyawan dalam institusi/lembaga lebih termotivasi adalah yang memiliki dorongan untuk meningkatkan produktivitas, kualitas, kuantitas, dan komitmen.

$$
\text { Penelitian ini dilakukan di PT }
$$

BNI Lifelnsurance. BNI Life merupakan perusahaan yang bergerak di bidang asuransi yang menyediakan berbagai produk asuransi seperti asuransi jiwa, kesehatan, pendidikan, investasi syariah dan pensiun. Pendirian BNI Life, sejalan dengan kebutuhan perusahaan induknya, PT Bank Negara Indonesia (Persero) Tbk, untuk menyediakan layanan dan jasa keuangan terpadu bagi semua nasabahnya.

Pada tahun 2016 BNI Life divisi employee benefit merencanakan target kinerja yang termuat dalam sales performancereport. Namun dalam target kinerja sampai dengan november 2016 belum dapat mencapai target yang telah ditentukan, sehingga masih terdapat gap antara target dan realisasinya seperti yang tercantum pada sales performance report divisi employee benefit performance periode Januari s/d November 2016 sebagai berikut: 
Tabel 1. Business Banking Performace. Sumber: Sales Performance Report divisi employee benefit periode Januari s/d November 2016

\begin{tabular}{|c|c|c|c|c|c|c|c|}
\hline \multirow{3}{*}{ NO } & \multirow{4}{*}{$\begin{array}{c}\text { Business } \\
\text { Banking } \\
\text { Team }\end{array}$} & \multirow{4}{*}{ Sales } & \multicolumn{5}{|c|}{ Target YTD } \\
\hline & & & \multirow[b]{2}{*}{ Closing (Volume) } & \multirow[b]{2}{*}{ Target YTD } & \multirow[b]{2}{*}{ GAP } & \multirow[b]{2}{*}{$\%$} & Archievment \\
\hline & & & & & & & VS Minimum \\
\hline & & & & & & & Target \\
\hline 1 & Corporate & 76 & 229.948 .894 .065 & 333.619 .750 .000 & 103.670 .855 .935 & $68,93 \%$ & Tidak \\
\hline & Bussiness & & & & & & Tercapai \\
\hline 2 & Commercial & 102 & 7.957 .651 .031 & 162.301 .500 .000 & 154.343 .848 .969 & $4,90 \%$ & Tidak \\
\hline & \& Small & & & & & & Tercapai \\
\hline & Bussniness & & & & & & \\
\hline 3 & Consumer & 144 & 12.210 .454 .130 & 405.753 .750 .000 & 393.543 .295 .870 & $3,01 \%$ & Tidak \\
\hline & & & & & & & Tercapai \\
\hline & TOTAL & 322 & 250.116 .999 .226 & 901.675 .000 .000 & 651.558 .000 .774 & $28 \%$ & \\
\hline
\end{tabular}

Pada tabel di atas dapat terlihat bahwa divisi employee benefit mempunyai 3 bagian yang terdiri dari corporate business, commercial dan small business, dan consumer. Masing-masing dari bagian tersebut belum memenuhi target yang ditetapkan oleh manajemen. Prosentase antara realisasi dan target yang ditetapkan dari bagian corporate business sebesar $68.93 \%$, commercial dan small business $4,90 \%$, dan bagian consumer $3.01 \%$.

Jika prosentase tersebut dijumlahkan sebesar $28 \%$ dari total $100 \%$ target yang ditetapkan. Informasi tersebut menjadi indikasi bahwa telah terjadi penurunan kinerja karyawan. Hal ini menjadi indikasi adanya masalah pada kinerja karyawan di perusahaan tersebut. Oleh sebab itu perlu dikaji secara empiris mengenai faktorfaktor yang dapat mempengaruhi kinerja karyawan pada PT BNI Life Insurance khususnya pada divisi employee benefit.
Motivasi seseorang mempengaruhi cara mereka bersikap dan bekerja sehingga manajeman wajib mengatahui karakteristik karyawan. Maslow (Asim, 2013), menyatakan motivasi sebagai suatu reaksi yang diawali dengan adanya kebutuhan yang menumbuhkan keinginan atau upaya mencapai tujuan yang selanjutnya menimbulkan ketegangan yaitu keinginan yang belum terpenuhi, yang kemudian menyebabkan timbulnya tindakan yang mengarah kepada tujuan dan akhirnya akan memuaskan keinginan.

Selanjutnya Maslow (Asim, 2013) juga menyatakan bahwa motivasi manusia berkembang secara berurutan sesuai dengan lima tingkat kebutuhan, kebutuhan ini adalah fisiologis (lapar, haus), keamanan (perlindungan), sosial (diterima, milik kelompok tertentu), harga diri (kepercayaan diri, prestasi, penghargaan, status, pengakuan), dan aktualisasi diri (menyadari potensi seseorang untuk 
terus mengembangkan diri). Menurut Maslow, orang mulai di bagian bawah hirarki, memastikan bahwa kebutuhan fisiologis, seperti lapar adalah pertama yang dipenuhi. Selanjutnya mereka memotivasi sendiri, secara bertahap, untuk mencapai tingkat kebutuhan yang lebih tinggi seperti keselamatan, sosial, harga diri, dan aktualisasi diri.

Penelitian ini bertujuan untuk mengetahui: (1) Motivasi terhadap kinerja karyawan pada PT BNI Life Insurance; (2) Motivasi terhadap kepuasan kerja PT BNI Life Insurance;(3) Pengaruh motivasi terhadap kinerja karyawan yang di mediasi oleh kepuasan kerja di PT BNI Life Insurance;(4) Pengaruh lingkungan kerja terhadap kinerjakaryawan PT BNI Life Insurance;(5) Pengaruh lingkungan kerja terhadap kepuasan kerja pada PT BNI Life Insurance; (6) Pengaruh lingkungan kerja terhadap kinerja karyawan yang di mediasi oleh kepuasan kerja di PT BNI Life Insurance; (7) Pengaruh kepuasan kerja terhadap kinerja karyawan PT BNI Life Insurance.

\section{KAJIAN TEORITIK Motivasi}

Motivasi adalah menemukan kebutuhan karyawan dan membantu untuk mencapainya dalam proses yang halus. Memotivasi karyawan bertujuan untuk memperluas keterampilan mereka dalam memenuhi tuntutan organisasi. Setiap manajer harus memiliki tanggung jawab untuk bekerja dengan karyawan, mengetahui kebutuhan masing-masing dan menempatkan mereka berdampingan dengan kebutuhan organisasi. Pendapat ini didukung oleh pendapat Ludhans (dalam Kiruja dan Mukuru (Kiruja E. K., 2013), yang menyatakan motivasi tentang memberi karyawan gabungan yang tepat dari bimbingan, arahan, sumber daya dan imbalan agar mereka terinspirasi dan tertarik untuk bekerja dengan cara yang kita inginkan. Karyawan adalah salah satu aset yang paling berharga. Karyawan yang termotivasi lebih akan tinggal dan membantu membangun bisnis. Membuat karyawan termotivasi akan membangun bisnis dan juga mengurangi biaya rekrutmen dan pelatihan.

Mullins (Kiruja E. K., 2013), menyatakan bahwa memotivasi karyawan secara efektif adalah salah satu fungsi yang paling penting dari seorang manajer. Ada bukti yang menunjukkan bahwa organisasi yang menghadapi tantangan dalam mempertahankan karyawan karena peluang yang terbatas untuk kemajuan organisasi dan pasar tenaga kerja yang kompetitif saat ini.

Hilangnya karyawan merupakan hilangnya keterampilan, pengetahuan dan pengalaman yang dapat membuat dampak ekonomi yang signifikan dan biaya untuk perusahaan serta berdampak pada kebutuhan pelanggan. Manager yang dapat memotivasi karyawan akan membantu organisasi dalam meningkatkan retensi karyawan. 


\section{Lingkungan Kerja}

Lingkungan kerja merupakan variabel bebas dalam penelitian ini. Menurut Ruchi (Leblebici, 2012), kinerja karyawan ditentukan oleh tingkat yang lebih pada lingkungan di mana mereka bekerja.Lingkungan kerja melibatkan semua aspek yang bertindak dan bereaksi pada tubuh dan pikiran dari karyawan. Di bawah psikologi organisasi, fisik, mental dan lingkungan sosial di mana karyawan bekerja dan pekerjaan yang harus dianalisis untuk efektivitas yang lebih baik dalam meningkatkan kinerja. Tujuan utamanya adalah untuk menghasilkan lingkungan yang menjamin kemudahan dalam bekerja dan menghilangkan semua penyebab frustrasi, kecemasan dan kekhawatiran. Jika lingkungan kerja menyenangkan, maka kelelahan, monoton dan kebosanan diminimalkan dan kinerja bisa maksimal.

Dalam melihat hubungan lingkungan kerja terhadap kinerja karyawan peneliti mengacu pada grand theory dua faktor Hezberg (Harsuko., 2011). Konsep ini menyebutkan faktor intrinsik dan faktor ekstrinsik yang berperan dalam kinerja karyawan. Faktor intrinsik meliputi:

a) Pekerjaan yang menyenangkan mengandung arti sejauh mana pekerjaan memberikan rasa senang bagi pelaku pekerjaan itu.

b) Kesempatan berprestasi mengandung arti sejauh mana pekerjaan yang dilakukan memberi kesempatan untuk menunjukkan prestasi bagi pelaku pekerjaan itu. c) Meningkatkan keterampilan mengandung arti sejauh mana pekerjaan yang dilakukan memberi kesempatan untuk meningkatkan keterampilan bagi para pelakunya.

Sedangkan faktor ekstrinsik meliputi:

a) Imbalan mengandung arti sejauh mana semua pendapatan baik uang maupun barang dapat mengganti jasa yang diberikan pelakunya.

b) Lingkungan kerja mengandung arti sejauh mana lingkungan kerja memberikan dukungan bagi pelakunya dalam melaksanakan pekerjaan

c) Kebijakan perusahaan yang memotivasi mengandung arti sejauh mana kebijakan perusahaan memberikan dorongan kepada pelakunya untuk bekerja giat.

\section{Kepuasan Kerja}

Kepuasan kerja dalam penelitian ini merupakan variabel mediasi.Kepuasan kerja menurut Fitzgerald (1994), merupakan salah satu kriteria untuk menetapkan kesehatan organisasi, memberikan jasa yang efektif dan sangat tergantung pada sumber daya manusia dan kepuasan kerja yang dialami oleh karyawan. Kepuasan kerja juga telah didefinisikan sebagai keadaan emosi positif yang dihasilkan dari kenikmatan seorang pekerja yang berasal dari pekerjaan mereka.

Rose (2001), menyatakan telah melihat kepuasan kerja sebagai konsep dua dimensi yang terdiri dari dimensi kepuasan 
intrinsik dan ekstrinsik.Sumber intrinsik kepuasan tergantung pada karakteristik individu dari seseorang, seperti kemampuan untuk menggunakan inisiatif, hubungan dengan penyelia, atau pekerjaan yang karyawan benar-benar lakukan, ini merupakan aspek simbolik pada pekerjaan.

Sumber ekstrinsik kepuasan yang situasional dan tergantung pada lingkungan, seperti gaji, promosi, atau keamanan kerja; ini merupakan imbalan materi keuangan atau keuntungan dari pekerjaan. Kedua aspek pekerjaan ekstrinsik dan intrinsik harus bisa mewakili dalam ukuran gabungan dari kepuasan kerja secara keseluruhan.

\section{Kinerja Karyawan}

Dalam penelitian ini kinerja karyawan merupakan variabel terikat. Menurut Kiruja dan Elegwa (Kiruja E. K., 2013), Kinerja karyawan merupakan fungsi dari kemampuan dan motivasi, di mana kemampuan terdiri dari keterampilan, pelatihan dan sumberdaya yang diperlukan untuk melakukan tugas dan motivasi digambarkan sebagai kekuatan batin yang mendorong individu untuk bertindak terhadap sesuatu. Kinerja karyawan mempengaruhi seberapa banyak mereka memberi kontribusi kepada organisasi, yang meliputi kuantitas output, kualitas output, jangka waktu output, kehadiran di tempat kerja, dan sikap kooperatif.

Menurut Eysenck (Kiruja E. K., 2013), Kinerja karyawan juga dapat ditentukan sebagai ke- mampuan seseorang untuk tampil dan juga termasuk kesempatan dan kesediaan untuk mengerjakan tugasnya. Makna kesediaan untuk melakukan tugasnya berarti bahwa adanya keinginan karyawan dalam menempatkan banyak usaha terhadap pekerjaan mereka.

Pendapat tersebut didukung oleh Sinha (2001), bahwa kinerja karyawan tergantung pada kemauan dan juga keterbukaan karyawan itu sendiri untuk melakukan pekerjaan mereka. Lebih lanjut ia menyatakan bahwa dengan memiliki kemauan dan keterbukaan karyawan dalam melakukan pekerjaan mereka, itu bisa meningkatkan produktivitas karyawan yang juga mengarah ke kinerja.

Teori tentang kinerja karyawan yang dikemukakan oleh As'ad (Harsuko., 2011) menyebutkan bahwa perbedaan kinerja antara orang yang satu dengan lainnya dalam situasi kerja adalah karena perbedaan karakteristik dari individu. Di samping itu, orang yang sama dapat menghasilkan kinerja yang berbeda di dalam situasi yang berbeda pula. Selanjutnya kinerja itu garis besarnya dipengaruhi oleh dua hal, yaitu faktor-faktor individu (motivasi dan kepuasan) dan faktorfaktor situasi (lingkungan kerja). Namun pendapat ini masih belum menerangkan tentang prosesnya. Khusus, yang menyangkut proses ada dua teori yaitu:

1. Path Goal Theory. Teori ini dikemukakan oleh Locke dari dasar teori Lewin's (Harsuko., 2011) berpendapat bahwa tingkah laku manusia banyak didasarkan untuk mencapai suatu 
tujuan. Teori yang lain dikemukakan oleh George-poulos yang disebut Path Goal Theory yang menyebutkan bahwa kinerja adalah fungsi dari facilitating Process dan Inhibiting process. Prinsip dasarnya jika seseorang melihat bahwa kinerja yang tinggi itu merupakan jalur untuk memuaskan needs (goal) tertentu, maka ia akan berbuat mengikuti jalur tersebut sebagai fungsi dari level of needs yang bersangkutan (facilitating process.

2. Teori Attribusi atau expectancy theory. Menurut As'ad (Harsuko., 2011) teori ini pertama kali dikemukakan oleh Heider (1958). Pendekatan teori atribusi mengenai kinerja dirumuskan $\mathrm{P}=$ $\mathrm{MXA}$, di mana $\mathrm{P}=$ performance; $\mathrm{M}=$ motivation; $\mathrm{A}=$ ability. Teori ini menjadi konsep sangat populer oleh ahli lainya. Berpedoman pada formula diatas, menurut teori ini kinerja adalah hasil interaksi antara motivasi dengan ability (kemampuan dasar). Dengan demikian, orang yang tinggi motivasinya tetapi memilki ability yang rendah akan menghasilkan kinerja yang rendah. Begitu pula halnya dengan orang yang mempunyai ability tinggi tetapi rendah motivasinya.

\section{METODOLOGI PENELITIAN}

Unit analisis atau objek yang akan diteliti adalah PT BNI Life Insurance. PT BNI Life Insurance (BNI Life) merupakan perusahaan asuransi yang menyediakan layanan asuransi seperti Asuransi
Jiwa, Asuransi Kesehatan, Asuransi Pendidikan, Asuransi berbasis Investasi, Pensiun dan Syariah. Dalam menyelenggarakan kegiatan usahanya, BNI Life telah memperoleh izin usaha di bidang asuransi jiwa berdasarkan surat dari Menteri Keuangan No. 305/ KMK.017/1997 tanggal 7 Juli 1997. Pendirian BNI Life, sejalan dengan kebutuhan perusahaan induknya, PT Bank Negara Indonesia (Persero) Tbk atau BNI, untuk menyediakan layanan dan jasa keuangan terpadu bagi semua nasabahnya (one-stop financial services).

Penelitian ini menggunakan metode kuantitatif dan hubungan kausal (causal effect). Sumber data yang digunakan peneliti adalah data primer. Metode pengumpulan data primer dalam penelitian ini melalui wawancara langsung dengan pihakpihak yang berhubungan dengan penelitian yang dilakukan. Sedangkan teknik pengumpulan data dalam penelitian ini menggunakan teknik observasi melalui media kuesioner. Selain itu peneliti juga melakukan pendekatan komunikasi. Penelitian ini menggunakan statistik inferensial. Metode ini membuat peneliti mampu untuk mengetahui karakteristik antara satu variabel dan variabel lainnya atau perbedaan antara satu atau dua lebih kelompok.

Berdasarkan deskripsi konseptual, review penelitian terdahulu, dan kerangka konseptual tersebut diatas, maka hipotesis yang diajukan dalam penelitian ini adalah sebagai berikut: 
$\mathrm{H}_{1}$ : Motivasi berpengaruh positif dan signifikan terhadap kinerja karyawan.

$\mathrm{H}_{2}$ : Motivasi berpengaruh positif dan signifikan terhadap kepuasan kerja.

$\mathrm{H}_{3}$ : Motivasi berpengaruh positif dan signifikan terhadap kinerja karyawan dimediasi oleh kepuasan kerja.

$\mathrm{H}_{4}$ : Lingkungan Kerja berpengaruh positif dan signifikan terhadap kinerja karyawan.

$\mathrm{H}_{5}$ : Lingkungan Kerja berpengaruh positif dan signifikan terhadap kepuasan kerja.

$\mathrm{H}_{6}$ : Lingkungan Kerja berpengaruh positif dan signifikan terhadap kinerja karyawan dimediasi oleh kepuasan kerja

$\mathrm{H}_{7}$ : Kepuasan Kerja berpengaruh positif dan signifikan terhadap kinerja karyawan.

\section{HASIL DAN PEMBAHASAN}

Hasil statistik membuktikan bahwa hipotesis yang telah diajukan, menunjukan beberapa hipotesis terbukti memiliki pengaruh dan signifikan, sedangkan lainnya tidak memiliki pengaruh karena memiliki hasil dibawah nilai kritis ttabel yakni 1.96.adapun pembahasannya adalah sebagai berikut:

1. Pengaruh motivasi terhadap kinerja karyawan

Dengan persamaan struktural menunjukan bahwa variabel motivasi terhadap kinerja karyawan memiliki nilai pengaruh yang sangat kuat, karena angka yang didapat melebihi nilai kritis t-tabel yakni 2.97 $>1.96$, maka peneliti menyimpulkan motivasi berpengaruh positif dan signifikan terhadap kinerja karyawan dengan hasil uji hipotesis menerima $\mathrm{H}_{\mathrm{I}}$ dan menolak $\mathrm{H}_{\mathrm{O}}$. Hasil penelitian ini didukung oleh peneletian sebelumnya yang dilakukan oleh Kiruja dan Mukuru (Kiruja E. K., 2013); Omollo (Omollo, 2015); Asim (Asim, 2013); Uzonna(Uzonna, 2013); Chintallo dan Mahadeo (Chintalloo), yang juga menyatakan bahwa motivasi berpengaruh terhadap kinerja karyawan.

Dapat disimpulkan bahwa semakin tinggi motivasi dari karyawan maka secara langsung akan meningkatkan kinerja dari karyawan tersebut. Oleh sebab itu hendaknya perusahaan mencari cara untuk menumbuhkan kembali motivasi dari karyawan dalam upaya untuk meningkatkan kinerja karyawan di PT BNI Life Insurance divisi employee benefit.

2. Pengaruh motivasi terhadap kepuasan kerja

Hipotesis kedua ini adalah mengukur antar variabel motivasi terhadap kepuasan kerja dan hasilnya adalah motivasi memiliki pengaruh yang signifikan terhadap kepuasan kerja dengan nilai $t$-value 2.31 lebih besar dari nilai kritis $t_{\text {-tabel }}$ 1.96 maka peneliti menyim-pulkan bahwa variabel motivasi terhadap kepuasan kerja memiliki pengaruh yang signifikan dan artinyadalam uji kedua ini peneliti menerima $\mathrm{H}_{2}$ dan menolak $\mathrm{H}_{0}$.

Hasil penelitian ini didukung oleh peneletian sebelumnya yang dilakukan oleh Oluseye, Amos, dan Abiola (Oluseye, 2014); Jehanzeb, Rasheed, Rasheed, dan Aamir 
(Jahanzeb, 2012); Raza, Akhtar, Husnain, dan Akhtar (Raza, 2015); Nyarko, Twumwaa, dan Adentwi (Nyarko, 2014); Khalid, Salim, dan Loke (Khalid, 2011), yang juga menyatakan bahwa motivasi berpengaruh positif dan signifikan terhadap kepuasan kerja. Maka dapat disimpulkan bahwa karyawan yang termotivasi dapat meningkatkan kepuasan kerja di PT $\mathrm{BNI}$ Life Insurance divisi employee benefit.

3. Pengaruh motivasi terhadap kinerja karyawan yang dimediasi kepuasan kerja

Uji hipotesis yang ketiga adalah mangukur pengaruh antar variabel motivasi terhadap kinerja karyawan yang dimediasi oleh kepuasan kerja dan hasilnya adalah memiliki pengaruh yang signifikan, hal tersebut dapat diketahui dengan melihat nilai t-value -2.32 lebih besar dari nilai $t_{\text {tabel }} 1.96$ maka peneliti menyimpulkan bahwa hasil penelitian ini kepuasan kerja memediasi hubungan antara motivasi terhadap kinerja karyawan yang bepengaruh signifikan dan artinya uji ketiga ini menerima $\mathrm{H}_{3}$ dan menolak $\mathrm{H}_{0}$.

Hasil penelitian ini didukung oleh penelitian sebelumnya yang dilakukan oleh Nurcahyani dan Idnyani (Nurcahyani, 2016); Mantauv (Mantauv, 2013); Novianti, Farida, dan Widiartanto (Novianti, 2015) yang menyatakan motivasi terhadap kinerja karyawan yang dimediasi oleh kepuasan kerja berpengaruh positif dan signifikan. Oleh sebab itu dapat disimpulkan bahwa kepuasan kerja memediasi hubungan motivasi terhadap kinerja karyawan di PT BNI Life Insurance divisi employee benefit.

4. Pengaruh lingkungan kerja
terhadap kinerja karyawan
Hipotesis keempat ini adalah mengukur variabel lingkungan kerja terhadap kinerja karyawan. Hasil me-nunjukan bahwa uji hipotesis antara kedua variabel ini menunjukan hasil yang tidak signifikan karena menunjukan hasil nilai t-value yang lebih rendah dari nilai $\mathrm{t}^{\mathrm{t}}$ tabel yakni $0.00<1.96$, sehingga hasil ini menunjukan lingkungan kerja tidak memiliki pengaruh yang signifikan terhadap kinerja karyaan, maka peneliti menolak $\mathrm{H}_{4}$ dan menerima $\mathrm{H}_{0}$.

Hasil penelitian ini didukung oleh penelitian sebelumnya yang dilakukan oleh Arianto (Arianto, 2013), yang menganalisis pengaruh kedisiplinan kerja, lingkungan kerja dan budaya kerja terhadap kinerja tenaga pengajar di yayasan pendidikan luar biasa kabupaten Demak, hasil penelitian menunjukan bahwa kedisiplinan kerja tidak berpengaruh terhadap kinerja, lingkungan kerja tidak berpengaruh terhadap kinerja, dan budaya kerja berpengaruh positif terhadap kinerja tenaga pengajar. Selain itu Logahan, Tjoe, dan Naga (Logahan, 2012) juga melakukan penelitian yang bertujuan untuk mengetahui pengaruh lingkungan kerja dan pemberian kompensasi terhadap kinerja karyawan.

Hasil penelitian menunjukan lingkungan kerja tidak memiliki pengaruh yang signifikan terhadap kinerja karyawan di CV Mum 
Indonesia, Kompensasi memiliki nilai signifikan sebesar $33.6 \%$, namun tidak berpengaruh terhadap kinerja karyawan yaitu sebesar 0.580 . Maka dapat disimpulkan bahwa variabel lingkungan kerja menurut responden di PT BNI Life Insurance divisi employee benefit tidak mempengaruhi kinerja.

\section{Pengaruh lingkungan kerja terhadap kepuasan kerja \\ Uji hipotesis yang kelima adalah} antara variabel lingkungan kerja terhadap kepuasan kerja, hasil menunjukan bahwa uji hipotesis antara kedua variabel ini menunjukan hasil t-value $2.97>t$ tabel 1.96 maka peneliti menyimpulkan variabel lingkungan kerja berpengaruh terhadap kepuasan kerja yang berarti hipotesis kelima ini menerima $\mathrm{H}_{5}$ dan menolak $\mathrm{H}_{0}$, karena hasil uji hipotesis menunjukan hasil yang baik.

Hasil penelitian ini didukung oleh penelitian sebelumnya yang dilakukan oleh Raziq dan Maulabakhsh (Raziq, 2015); Bakotic dan Babic(Bakotic, 2013); Jain dan Kaur (Jain, 2014);Atambo, Otundo, dan Nyamwamu (Atambo, 2013); Medina, Garza, dan Chein(Medina, 2013), yang menyatakan variabel lingkungan kerja berpengaruh positif dan signifikan terhadap kinerja karyawan. Maka dapat disimpulkan lingkungan kerja yang baik dapat meningkatkan kepuasan kerja karyawan PT BNI Life Insurance divisi employee benefit.

6. Pengaruh lingkungan kerja terhadap kinerja karyawan yang dimediasi olehkepuasan kerja
Hipotesis keenam ini adalah mengukur antar variabel lingkungan kerja terhadap kinerja karyawan yang dimediasi kepuasan kerja dan hasilnya adalah memiliki pengaruh yang signifikan. Hal tersebut dapat diketahui jalur variabel kepuasan kerja terhadap kinerja karyawan sebesar 3.36 lebih besar dari nilai ttabe1.96, maka peneliti menyimpulkan kepuasan kerja me-mediasi hubungan lingkungan kerja terhadap kinerja karyawan, maka hasil penelitian ini menerima $\mathrm{H}_{6}$ dan menolak $\mathrm{H}_{0}$.

Hasil penelitian ini didukung oleh penelitian sebelumnya yang dilakukan oleh Harahap dan Hidayat (Harahap, 2015); Santoso, Sampeadi, dan Apriono(Santoso, 2015)dengan hasil penelitian lingkungan kerja terhadap kinerja karyawan dengan mediasi kepuasan kerja berpengaruh positif dan signifikan. Maka dapat disimpulkan kepuasan kerja positif memediasi hubungan lingkungan kerja terhadap kinerja karyawan di PT BNI Life Insurance divisi employee benefit.

\section{Pengaruh kepuasan kerja terhadap kinerja karyawan}

Uji hipotesis yang terakhir adalah antara variabel kepuasan kerja terhadap kinerja karyawan. Hasil yang didapatkan adalah nilai tvalue -2.73 lebih besar dari $t$ tabel 1.96 , dengan hasil ini bahwa uji hipotesis antara kepuasan kerja terhadap kinerja karyawan memiliki pengaruh dan artinya $\mathrm{H}_{7}$ pada penelitian ini diterima dan $\mathrm{H}_{0}$ ditolak.

Hasil penelitian ini juga didukung oleh penelitian sebelum- 
nya yang dilakukan oleh Khan, Nawaz, Aleem, dan Hamed (Khan, 2012); Javed, Balouch, dan Hassan (Javed, 2014); Fadlallh (Fadlallh, 2015); Hira dan Waqas (Hira, 2012); dan Platis, Reklitis, dan Zimeras (Platis, 2014), yang menyatakan kepuasan kerja mempunyai pengaruh yang signifikan terhadap kepuasan kerja. Maka dapat disimpulkan bahwa karyawan yang mempunyai kepuasan kerja yang tinggi maka secara langsung dapat meningkatkan kinerja dari karyawan tersebut.

\section{KESIMPULAN DAN SARAN}

Dari hasil penelitian yang telah dilakukan untuk mengetahui pengaruh motivasi, dan lingkungan kerja terhadap kinerja karyawan dengan kepuasan kerja sebagai variabel mediasi di PT BNI Life Insurance divisi Employee Benefit, maka dapat disimpulkan sebagai berikut:

$\mathrm{H}_{1}$ : Pengaruh Motivasi terhadap Kinerja Karyawan. Uji hipotesis pertama dengan hasil yang telah didapatkan menunjukan bahwa variabel motivasi terhadap kinerja karyawan memiliki nilai pengaruh yang kuat karena angka yang didapati melebihi nilai kritis ttabel yakni sebesar 1.96 dengan tvalue 2.97. Maka peneliti menyimpulkan variabel motivasi memiliki pengaruh signifikan terhadap kinerja karyawan dan hasil menunjukan bahwa uji hipotesis ini menerima $\mathrm{H}_{1}$ dan menolak $\mathrm{H}_{0}$.

$\mathrm{H}_{2}$ : Pengaruh Motivasi terhadap Kepuasan Kerja. Hipotesis kedua ini adalah mengukur antar variabel motivasi terhadap kepuasan kerja dan hasilnya adalah motivasi memiliki pengaruh yang signifikan terhadap kepuasan kerja dengan nilai t-value 2.31 lebih besar dari nilai kritis $t_{\text {-tabel }} 1.96$ maka peneliti menyimpulkan bahwa variabel motivasi terhadap kepuasan kerja memiliki pengaruh yang signifikan dan artinya dalam uji kedua ini peneliti menerima $\mathrm{H}_{2}$ dan menolak $\mathrm{H}_{0}$.

$\mathrm{H}_{3 \text { : }}$ Pengaruh Motivasi yang dimediasi oleh Kepuasan kerja terhadap Kinerja Karyawan.Uji hipotesis yang ketiga adalah mengukur pengaruh antar variabel motivasi terhadap kinerja karyawan yang dimediasi oleh kepuasan kerja dan hasilnya adalah memiliki pengaruh yang signifikan, hal tersebut dapat diketahui dengan melihat nilai t-value -2.32 lebih besar dari nilai $t_{-t a b e l} 1.96$ maka peneliti menyimpulkan bahwa hasil penelitian ini kepuasan kerja memediasi hubungan antara motivasi terhadap kinerja karyawan bepengaruh signifikan dan artinya uji ketiga ini menerima $\mathrm{H}_{3}$ dan menolak $\mathrm{H}_{0}$.

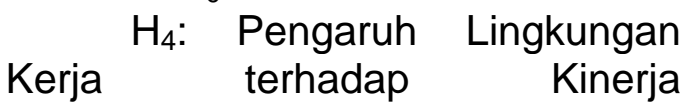
KaryawanHipotesis keempat ini adalah mengukur variabel lingkungan kerja terhadap kinerja karyawan. Hasil menunjukan bahwa uji hipotesis antara kedua variabel ini menunjukan hasil yang tidak signifikan karena menunjukan hasil nilai t-value yang lebih rendah dari nilai $t_{\text {tabel }}$ yakni $0.00<1.96$, sehingga hasil ini menunjukan lingkungan kerja tidak memiliki pengaruh yang signifikan terhadap 
kinerja karyaan, maka peneliti menolak $\mathrm{H}_{4}$ dan menerima $\mathrm{H}_{0}$.

$\mathrm{H}_{5}$ : Pengaruh Lingkungan Kerja terhadap kepuasan kerja. Uji hipotesis yang kelima adalah antara variabel lingkungan kerja terhadap kepuasan kerja, hasil menunjukan bahwa uji hipotesis antara kedua variabel ini menunjukan hasil t-value $2.97>t_{\text {-tabel }} 1.96$ maka peneliti menyimpulkan variabel lingkungan kerja berpengaruh terhadap kepuasan kerja yang berarti hipotesis kelima ini menerima $\mathrm{H}_{5}$ dan menolak $\mathrm{H}_{0}$, karena hasil uji hipotesis menunjukan hasil yang baik.

$\mathrm{H}_{6}$ : Pengaruh Lingkungan Kerja yang dimediasi oleh Kepuasan Kerja terhadap Kinerja Karyawan. Hipotesis keenam ini adalah mengukur antar variabel lingkungan kerja terhadap kinerja karyawan yang dimediasi kepuasan kerja dan hasilnya adalah memiliki pengaruh yang signifikan.Hal tersebut dapat diketahui jalur variabel kepuasan kerja terhadap kinerja karyawan sebesar 3.36 lebih besar dari nilai $t_{\text {-tabel }}$ 1.96, maka peneliti menyimpulkan kepuasan kerja memediasi hubungan lingkungan kerja terhadap kinerja karyawan, maka hasil penelitian ini menerima $\mathrm{H}_{6}$ dan menolak $\mathrm{H}_{0}$.

$\mathrm{H}_{7}$ : Pengaruh Kepuasan kerja terhadap kinerja karyawan. Uji hipotesis yang terakhir adalah antara variabel kepuasan kerja terhadap kinerja karyawan. Hasilyang didapatkan adalah nilai t-

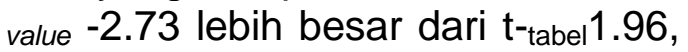
dengan hasil ini bahwa uji hipotesis antara kepuasan kerja terhadap kinerja karyawan memiliki pengaruh dan artinya $\mathrm{H}_{7}$ pada penelitian ini diterima dan $\mathrm{H}_{0}$ ditolak.

Berdasarkan hasil penelitian, maka disampaikan saran sebagai berikut: (1) Saran kepada perusahaan. Dari hasil penelitian di atas maka disarankan kepada perusahaan PT BNI Life Insurance khususnya divisi employee benefit harus mengatasi permasalahan kinerja karyawan ini sebaik mungkin, tidak ada satupun perusahaan yang tidak mengalami masalah kinerja karyawan, namun jika tidak disikapi dengan benar maka perusahaan akan mengalami kesulitan dalam menjalankan laju usahanya, mengapa? Karena man power yang dibutuhkan harus meninggalkan perusahaan karena sudah tidak bisa berkomitmen lebih lama lagi, disebabkan banyak hal yang salah satunya adalah motivasi yang menurun, lingkungan kerja yang kurang baik, dan kepuasan kerja yang menurun akhirnya menurunkan kinerja karyawan dan dampaknya akan menurunkan laba perusahaan.

Sebagaimana dijelaskan di atas bahwa banyak hal yang akan mempengaruhi kinerja karyawan maka faktor motivasi yang ditimbulkan perusahaan terhadap karyawannya begitu penting, tidak lain juga faktor lingkungan kerja penelitian menunjukan bahwa lingkungan kerja akan berdampak langsung terhadap kinerjakaryawan, maka hal ini perlu diperhatikan seperti membenahi penerangan ruangan kerja, menata kembali kondisi ruang kerja dan sebagainya. Kepuasan kerja juga berperan penting terhadap kinerja karyawan, 
karena apabila karyawan merasa puas dan terpenuhi segala kebutuhannya, maka karyawan akan meningkatkan kinerjanya. Agar ke-depannya tidak timbul lagi masalah kinerja karyawan.

Bagi peneliti selanjutnya, keluasan dalam menggunakan variabel begitu amat penting menentukan hasil yang dapat meingkatkan kinerja karyawan, kemampuan membuat kuesioner menjadi hal terpenting selanjutnya untuk mendapatkan hasil yang akurat.

Kemampuan responden dalam menjawab kuesioner secara baik menjadi amat penting dan diperlukan, tidak sedikit dari mereka mengisi dengan tidak baik sehingga hasil kuesioner menjadi tidak maksimal, agar hasil yang didapat juga memberikan dampak yang baik dalam menyajikan kesimpulan, oleh karenanya peneliti selanjutnya diharapkan mampu merampungkan teori sebanyak-banyaknya terkait apa saja variabel yang dibutuhkan untuk menggambarkan variabel teramati lebih sempurna, dan informasi tersebut bisa kita lihat dari jurnal yang diterbitkan peneliti terdahulu dan referensi buku-buku yang berkaitan dengan kinerja karyawan.

Masih banyak sekali variabel yang tingkat uji coba hasil yang baik dan signifikan untuk penelitian selanjutnya, maka usaha dan kerja keras peneliti selanjutnya dalam mendalami variabel-variabel yang teramati amat penting, maka sangat dibutuhkan kedalaman teori dan pengamatan yang ekstra lebih besar agar dapat menentukan variabel yang lebih baik dan dapat mengumpulkan informasi lebih akurat dan dipertanggungjawabkan. Informasi dan pengetahuan tersebut bisa didapatkan dari jurnal yang bisa dipertanggungjawabkan secara nasional maupun internasional dengan legalitas yang diakui, agar peneliti memiliki sumber penelitian yang lebih kaya dan lebih baik untuk melakukan penelitian di kemudian hari.

\section{DAFTAR PUSTAKA}

Arianto, D. A. (2013). Pengaruh kedisiplinan, lingkungan kerja dan budaya kerja terhadap kinerja tenaga pengajar. Jurnal Economia, 9(2), 191200.

Asim, M. (2013). Impact of motivation on employee performance with effect of training: specific to education sector of Pakistan. International Journal of Scientific and Research Publications, 3, 1-9.

Atambo, W. N. (2013). The effect of perceived work conditions on job satisfaction: A survey of the ministry of education field officers, Kenya. Global business and economics research journal, 2(5), 25-41.

Bakotic, D. \&. (2013). Relationship between working conditions and job satisfaction: The case of croatian shipbuilding company. International journal of business and social science, 4, 206-213.

Chintalloo, S. \&. (n.d.). Effect of motivation on employee's 
work performance at ireland blyth limited. London business research conference imperial college, (pp. 1-16).

Fadlallh, A. W. (2015). Impact of job satisfaction on employees performance an application on faculty of science and humanity studies university of salman bin abdul aziz al aflaj. International journal of innovation and research in educational science, 2 (1), 26-32.

Harahap, V. A. (2015). Pengaruh motivasi dan lingkungan kerja terhadap kinerja melalui kepuasan kerja sebagai variabel intervening. E-jurnal apresiasi ekonomi, 2(2), 5769.

Harsuko. (2011). Mendongkrak Motivasi dan Kinerja Pendekatan Pemeberdayaan $S D M$. Malang: UB Press.

Hartono, J. (2013). Metodologi Penelitian Bisnis (Salah Kaprah dan PengalamanPengalaman) (Edisi 6 ed.). Yogyakarta: BPFE.

Hira, A. \&. (2012). A study of job satisfaction and It's impact on the performance in the banking industry of pakistan. International journal of business and social science, 3, 174-180.

Jahanzeb, K. R. (2012). Impact of rewards and motivation on job satisfaction in banking sector of saudi arabia. International journal of business and social science, 3, 272-278.
Jain, R. \&. (2014). Impact of work environment on job satisfaction. International journal of scientific and research publication, 4(1), 18.

Javed, M. B. (2014). Determinants of job satisfaction and its impact on employee performance and turnover intentions. International journal of learning and development, 4, 120-139.

Khalid, K. S. (2011). The impact of rewards and motivation on job satisfaction in water utility industry. International conference on financial managament and economics, $11,35-41$.

Khan, A. H. (2012). Impact of job satisfaction on employee performance: an empirical study of autonomous medical institutions of pakistan. African journal of business management, 6(7), 26972705.

Kiruja, E. K. (2013). Effect of Motivation on Employee Performance In Public Middle Level Technical Training Institutions In Kenya. International Journal of Advances in Management and Economics, 2, 73-82.

Kiruja, E. K. (2013). Linking work environment with employee performance in public middle level TIVET institution in Kenya. International journal of advances in management and economics, 2, 83-91.

Leblebici, D. (2012). Impact of workplace quality on 
employee's productivity: Case study of a bank in turkey. Journal of business, economics, \& Finance, 1(1), 38-49.

Logahan, J. M. (2012). Analisis pengaruh lingkungan kerja dan pemberian kompensasi terhadap kinerja karyawan CM Mum indonesia. Binus business review, 3(1), 573586.

Mantauv, C. S. (2013). Kepuasan kerja merupakan variabel intervening pengaruh antara motivasi kerja dengan kinerja pegawai (studi empirik di badan penanggulangan bencana). E-jurnal apresiasi ekonomi, 2(1), 46-52.

Medina, J. M. (2013). The impact of stress and the working environment on job satisfaction and decision making among women entrepreneurs in mexico. International journal of business and social research, 3(3), 164-173.

Novianti, N. N. (2015). Pengaruh budaya organisasi dan motivasi kerja terhadap kinerja karyawan dengan kepuasan kerja sebagai variabel intervening. E-jurnal apresiasi ekonomi, 2(1), 105119.

Nurcahyani, N. M. (2016). Pengaruh kompensasi dan motivasi terhadap kinerja karyawan dengan kepuasan kerja sebagai variabel intervening. E-jurnal manajemen UNUD, 5(1), 500-532.
Nyarko, K. T. (2014). The influence of motivation on the job satisfaction of junior high school teachers in Gana. Journal of education and practice, 5, 202-209.

Oluseye, O. O. (2014). Effect of motivation on job satisfaction of selected sales representatives. Journal of educational and Social Research, 41, 197-203.

Omollo, P. A. (2015). Effect of motivation on employee performance of commercial bank in Kenya: A Case Study of Kenya commercial Bank in Migori County. International journal of human resources studies, 5, 87-103.

Platis, C. H. (2014). Relation between job satisfaction and job performance in healthcare services. Social and behavioral science, 175, 480-487.

Raza, M. F. (2015). The impact of intrinsic motivation on employee's job satisfaction. Management and organization studies, 2, 8088.

Raziq, A. \&. (2015). The impact of working environment on job satisfaction. Procedia Economics and finance, 23, 717-725.

Santoso, S. P. (2015). Pengaruh lingkungan kerja dan kompensasi terhadap kinerja karyawan dengan kepuasan kerja sebagai variabel interve-ning pada koperasi agrobisnis tarutama 
nusantara jember. E-jurnal manajemen UNUD, 5(1), 4.

Uzonna, U. R. (2013). Impact of motivation on employee performance: A Case study of creditWest Bank Cyprus. Journal of Economics and International Finance, 5, 199211. 